\title{
Educação no Brasil e o ensino de História
}

Daniela Teles da Silva*

Resumo: Neste trabalho é realizada uma análise da evolução do ensino de História no Brasil. Para tal, é apresentada a história da educação no Brasil com foco principal na disciplina de História. A finalidade é a de compreender e comparar a evolução do ensino com o surgimento da História enquanto disciplina. Portanto, realizou-se uma contextualização histórica que mostra a evolução do ensino de História de acordo com as diferentes fases da educação no país. O objetivo principal é compreender a função da disciplina de História e destacar sua importância em sala de aula de modo a construir conhecimento, formar consciência histórica e crítica da sociedade.

Palavras- chave: História da Educação; Evolução do ensino de História; História como disciplina

Abstract: In this paper it is accomplished an analysis of the Brazilian History teaching evolution. For such, it is presented the education history in Brazil focusing in History as school subject. The objective is to understand and to compare the teaching evolution with the History emergence as school subject. Therefore, it was done a historical contextualization which shows the evolution of the History teaching according to differents educational stages in the country. The main objective is to understand the function of the History as school subject and to emphasize its importance in class in order to built knowledge and to built historical and critical awareness to society.

Keywords: History of Education; History Teaching Evolution; History as school Subject

\footnotetext{
${ }^{*}$ Graduação em Licenciatura em História pela Universidade Estadual do Centro-Oeste (UNICENTRO

- PR). Pós-Graduação em Metodologia do Ensino de História do Brasil. daniielateless@ gmail.com
} 


\section{Introdução}

O fato de o Brasil ter sido colônia de exploração portuguesa desde meados de 1500 influenciou diretamente a concepção da educação brasileira (cf. CERRI, 2013: 168-169). Fundada nas bases dos modelos europeus - principalmente em relação aos processos educacionais e escolares que surgem na Europa no século XVIII - a fundamentação da educação regular no Brasil passou por três fases distintas, marcadas pela participação jesuíta, as Reformas Pombalinas e a vinda da família real portuguesa em meados de 1808 a 1821. Fatos que criam os moldes do ensino no país (cf. GHIRALDELLI, 2001: 13).

Inicialmente, o ensino deixado a cargo da Companhia de Jesus apresenta grande conotação religiosa, baseado na história bíblica e nos princípios pregados pelos padres jesuítas. Posteriormente, a partir das ideias do Marquês de Pombal, a forma de ensino começa a vincularse a bases filosóficas diretamente influenciadas pelo Iluminismo europeu do século XVIII. Com a Constituição de 1824 - quando o Brasil se constitui Império - percebe-se a necessidade da implementação de escolas e universidades no Brasil, resultando no primeiro sistema nacional de educação (cf. GHIRALDELLI, 2001: 13-17), (cf. MACIEL, SHIGUNOV, 2006: 469).

A partir da Proclamação da República em 1889, buscava-se o progresso do país que já se mostrava bastante atrasado em relação à Europa. A educação filosófica foi substituída pela educação moral e cívica, visto que neste período o ensino buscava atender os interesses do Estado, incitando o patriotismo em prol de um desenvolvimento da nação (cf. CERRI, 2010: 264-265), (cf. MENEZES, 2011: 2).

Nesta busca pelo progresso, grandes mudanças políticas, econômicas e sociais ocorrem, principalmente no século XX, o qual representa um período de mudanças vinculadas também à educação. Juntamente com a Ditadura Militar e o processo de redemocratização, que comportam o período de 1964 a 1988 com a reestruturação e elaboração da nova Constituição brasileira, novos ideais voltados à educação são pensados e formulados. Importantes leis e diretrizes educacionais são criadas e modificadas, fato que foi de fundamental importância para o desenvolvimento da disciplina de História e a educação em geral no Brasil (cf. FONSECA, 2003: 25-26).

É importante ressaltar que a História como ciência está estabelecida há centenas de anos, entretanto, no Brasil apenas em 2001 se consolida de fato como disciplina nos currículos escolares. Identificando esta defasagem do ensino de História no país, este artigo propõe 
analisar os objetivos da disciplina em sala de aula, com base em uma contextualização entre a evolução da disciplina com os acontecimentos que marcam a evolução do próprio ensino no Brasil.

Acerca deste tema, diversos autores abordam a evolução da educação no Brasil em diferentes recortes históricos, demonstrando a relação entre o contexto histórico e a função da História enquanto disciplina. Como analisa Marc Ferro (1983) a História em sala de aula tem forte relação com a história de toda a sociedade: uma complementa a outra. Sendo a História ensinada reflexo da sociedade em que o professor e os alunos estão inseridos, criam-se as bases para o conhecimento "sócio-histórico" dos mesmos (cf. FERRO, 1983: 11).

Cerri (2001) baseia-se na corrente marxista do século XIX. Neste trabalho são demonstradas questões que surgiram a partir da mesma, como a mudança nas práticas, nos objetivos e nos temas de ensino. Desta forma, aborda temas como a tomada da consciência histórica, o senso crítico e o saber histórico e escolar, formulando a identidade social.

Ghiraldelli (2001) destaca-se ao apresentar a história da educação no Brasil desde o período colonial até parte do governo de Fernando Henrique Cardoso, em 1998. O autor divide o seu trabalho em dois campos: o primeiro retrata a política educacional e o segundo as ideias pedagógicas e suas mudanças.

Fonseca (2003) identifica os vários percalços pelos quais a educação e a disciplina de História passaram, desde 1964 com o início da ditadura militar, censura e restrição do ensino, até 1997 com a publicação dos Parâmetros Curriculares Nacionais. A autora apresenta o constante crescimento de lutas políticas e culturais nos anos 1980 e 1990, e como resultaram em melhorias significativas na educação, auxiliando na produção historiográfica do século XX. A partir dos conceitos de "história tradicional" e a "história nova", a autora apresenta as diferentes análises na interpretação e no ensino de História.

O trabalho de Bittencourt (2004) apresenta correntes historiográficas e as mudanças que ocorrem nos métodos ao longo do tempo. Busca explicitar as várias fases do ensino de História e as mudanças nos materiais didáticos, demonstrando a função da escola e do professor na construção das identidades.

Identificando nos trabalhos citados um espaço para análise acerca das práticas pedagógicas e da evolução do ensino de História no Brasil, este trabalho apresenta a história da educação, com foco principal na disciplina e ensino de História. Com tal objetivo, são expostos os marcos e a trajetória da educação e evolução da disciplina. A ideia principal é a de 
compreender e comparar o progresso do ensino com o surgimento da História enquanto disciplina, demonstrar a evolução e analisar o ensino em sala de aula, de modo a construir conhecimento e formar consciência histórica e crítica da sociedade.

\section{Uma contextualização da evolução do ensino de História no Brasil}

A História enquanto Ciência existe há milhares de anos, porém apenas no século XIX ela se desdobra e se denomina uma disciplina escolar, quando começam surgir seus primeiros manuais de ensino. No Brasil a concepção do ensino da disciplina se deu por influência do modelo francês, voltado à história dos heróis e seus grandes feitos, tendo por objetivo incitar a moral e o civismo (cf. CERRI, 1999: 138), (cf. ALVES, CENTENO, 2009: 482-483), (cf. MENEZES, 2011: 5-6). Portanto, a dita "história tradicional" ou positivismo histórico, concebia-se através de "grandes acontecimentos diplomáticos, políticos e religiosos do passado" (FONSECA, 2003: 41)

O processo de desenvolvimento da educação no Brasil apresenta várias fases, de acordo com os governos e momentos políticos. Da mesma forma, a História como ciência e disciplina passou por diferentes períodos buscando desempenhar e cumprir determinados papéis na sociedade. "A história nunca se basta; ela sempre se destina a alguém" (JENKINS, 2001: 40).

O estudo de História, baseado no modelo tradicional, apresentava conteúdos como a história cristã e eurocêntrica, remetendo apenas a história do ocidente - que era considerado mais desenvolvido - excluindo o oriente. Eram disciplinas como "História Sagrada, Antiga, da Idade Média, da Idade Moderna e, após 1850, da Idade Contemporânea” (DIAS, 2008: 84), mais tarde sendo incorporada a História do Brasil com o objetivo de incentivar o patriotismo.

No início era ensinada a História Sagrada, pois fazia parte da doutrina religiosa católica dos padres jesuítas. Essa forma de ensino permaneceu por muitos anos, mesmo depois da expulsão dos jesuítas e da separação entre Estado e Igreja (cf. BITTENCOURT, 2004: 62).

Percebe-se que o ensino no Brasil se inicia submetido e fortemente vinculado a uma ordem religiosa e se modifica em busca dos interesses do Estado. Da mesma forma, o ensino de História, desde sua criação, passou por um longo processo de mudança.

Várias transformações políticas ocorrem ao longo do tempo, afetando também a concepção do ensino, principalmente tratando-se de História, pois como disciplina, a História é o estudo do passado. Ou seja, os historiadores estudam e interpretam o passado vinculados ao

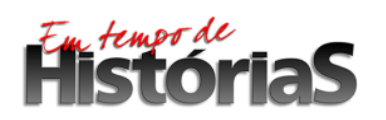

(PPGHIS/UnB) №. 32, Brasília, Jan - Jul 2018 ISSN 2316-1191 
meio político, cultural, social e até mesmo nacional. Neste sentido, a História serve a sociedade quando há alguma intenção para que determinado assunto, momento ou período seja estudado (cf. BOURDÉ, MARTIN, 1983: 200), (cf. JENKINS, 2001: 40-41).

Em 1838 com a fundação do Instituto Histórico e Geográfico do Brasil (IHGB), a História ganha maior espaço no âmbito disciplinar. Neste momento são determinadas metodologias de ensino da disciplina no país, pois o objetivo do IHGB era o de escrever a história oficial do Brasil (cf. DIAS, 2008: 82).

O ideal de um Instituto Histórico surge em 1827, vinculado à consolidação da independência do país em 1822, tendo por objetivo definir a identidade própria da população brasileira. Neste momento a tarefa da disciplina vincula-se diretamente a esse propósito, tendo em vista que a produção historiográfica brasileira permanecia fortemente influenciada pelo modelo europeu do século XIX, que inicialmente voltou-se a produções elitistas e iluministas, tendo caráter linear, progressivo, católico e conservador (cf. GUIMARÃES, 1988: 6-14).

Deste modo, sócios e membros do IHGB - que também exerciam funções de educadores - colaboraram de maneira intensa para a produção intelectual, auxiliando na criação e introdução de disciplinas escolares, como também por meio de publicações em jornais, periódicos e obras literárias (cf. MENDONÇA et al., 2013: 995).

Além do desejo de fundar uma historiografia nacional e original, há a intenção de não só ensinar e divulgar conhecimentos, como formular uma história que, a exemplo dos demais modelos europeus, se dedicasse à exaltação e glória da pátria (SCHWARCZ, 1993: 102).

Definindo o que é ser brasileiro, a historiografia encarrega-se de definir também "o outro". Diferenciando o brasileiro dos demais, buscando retratar um "Brasil civilizado", a história acaba por excluir algumas das próprias camadas sociais brasileiras, bem como os índios e negros que não eram considerados civilizados. Portanto, a historiografia deste período foi excludente e depreciativa, levando em consideração que era produzida, inicialmente, pela elite letrada que frequentava o meio acadêmico (cf. GUIMARÃES, 1988: 7-9).

Em 1851 através da linguística, arqueologia e etnografia, o IHGB visava estudar a população indígena que ainda era vista como "o outro", inferior em relação à "civilização branca", buscando, desta forma, argumentos científicos para demonstrar essa inferioridade (cf. GUIMARÃES, 1988: 11).

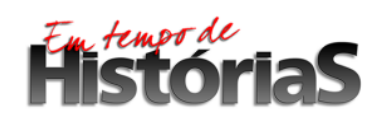


Questões como limites, fronteiras, e outros aspectos ligados à identidade da nação, foram vinculados à História, dando-lhe caráter político, uma vez que torna-se função da historiografia analisar e escrever a história do país (cf. GUIMARÃES, 1988: 15-16) buscando exaltar a nação e ao mesmo tempo inserir o Brasil no "mundo europeu”, difundir o progresso, disfarçar as desigualdades sociais e a desordem, tendo o branco europeu como modelo, o que não condizia com a realidade social do país (cf. DIAS, 2008: 87), (cf. R.IHGB, 1839: 5-6).

Neste período, os ensinos de história moral, cívica e religiosa complementavam-se, deste modo a história dos santos serviam como exemplo de heroísmo, bravura, caráter, misturando-se com narrativas dos grandes homens da vida pública e seus feitos, que serviam como modelo a ser seguido. Correspondendo assim, a metodologia pedagógica da época.

Com a instauração da República em 1889, novos métodos de ensino ganham molde, objetivando mais uma vez, fortalecer o patriotismo e a identidade nacional, o que era amplamente abordado nos materiais da época, em especial, o livro didático (cf. BITTENCOURT, 2004: 62-64).

No fim do século XIX e início do século XX o conceito de cidadania ganha nova forma, a escola por sua vez acompanha as mudanças sociais, econômicas e políticas, resultando em uma ampliação nas pesquisas e no estudo de História, o que caracteriza a abordagem conhecida como "nova história" ou Escola dos Annales (cf. FONSECA, 2003:41-42).

Essas mudanças estão vinculadas, principalmente, a dois fatores de maior importância para a consolidação definitiva do ensino no país; sendo eles a Ditadura Militar (1964 - 1985) e o processo de redemocratização, a partir de 1983.

Durante o período militar os investimentos em educação sofrem queda considerável e o currículo escolar passa por mudanças significativas. Desde 1930 a disciplina de História era vista como ferramenta de uma educação política, ou seja, voltada aos interesses do Estado, ideal fortemente reutilizado no período militar, vinculado ao objetivo de formar cidadãos aptos apenas ao mercado de trabalho (cf. DIAS, 2008: 90).

A partir da Lei n. 5.692 criada pelos militares em 1971, a História como disciplina acaba sendo excluída do currículo escolar, dando lugar à disciplina de Estudos Sociais - "mistura confusa de história, geografia, organização social e política do Brasil e educação moral e cívica" (SILVA, 2007: 8) - que passa a difundir ideologias e propagandear o atual momento político, visto que o ensino era voltado aos interesses militares e à elite, dessa maneira, submetido ao ideal de segurança nacional, buscando promover a economia (cf. FONSECA, 2003: 15-16).

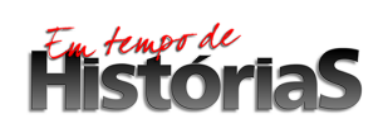


O processo de redemocratização começa a ganhar molde em meados de 1983, e com ele, uma mudança no panorama da educação, com novos ideais que buscam libertar as ideias que foram reprimidas durante o período militar. Influenciados por ideais marxistas, como as lutas sociais, a disciplina de História ressurge preocupando-se em criar cidadãos críticos, não mais receptores de conhecimento, mas também produtores deste (cf. YAMAMOTO, 1997: 3639), (cf. FONSECA, 2003: 18-25).

Buscava-se vincular o ensino de História à formação de uma sociedade democrática. A partir de então, exclui-se a necessidade de contar a história voltada à moral cívica, dando lugar ao ensino direcionado à realidade do país e do meio social que o aluno estava inserido.

Com todo esse panorama a Constituição implementada em 1988 já prevê em seus moldes a necessidade do aumento dos investimentos voltados ao sistema educacional. Desta forma, percebe-se o reconhecimento do ensino como um importante passo para o desenvolvimento da sociedade que, juntamente com a intensificação de debates em torno da educação, resulta em importantes avanços, como a elaboração da Lei de Diretrizes e Bases para a Educação Nacional (LDB 9.394/96) em 1996 e em 1998 com o início do processo de criação de diretrizes para a disciplina de História (cf. FONSECA, COUTO, 2008: 105-108).

A História como disciplina passou por várias etapas até ser definitivamente (re)aceita no currículo escolar. Uma maior segurança em relação a sua permanência em salas de aula ocorre apenas em 2001, com a aprovação das Diretrizes Curriculares Nacionais dos Cursos de História. Neste texto é enfatizada a importância da reformulação e reestruturação do curso e da formação de profissionais qualificados para o ensino e pesquisa, com preocupação central na formação do historiador (cf. BRASIL, 2001: 5-9), (cf. FONSECA, COUTO, 2008: 105-108).

\section{O ensino de História em sala de aula}

O papel da História como disciplina vem sendo remodelado com o passar dos anos. Novas linhas de pensamento e métodos são incorporados ao ensino visando à compreensão do mundo, das diversas religiões, culturas e valores que permeiam a vivência do aluno. Aspirando cumprir com o seu principal ideal que é o de formar cidadãos críticos e questionadores, a História deve retratar, assim como refletir a respeito dos problemas e da sociedade em que o aluno se insere. 
Políticas educacionais buscam modificar a forma de se escrever/produzir os materiais de apoio necessários para que o ensino se expresse de forma clara e justa. Entretanto, o papel da História como disciplina deve ser o de instigar o pensamento crítico do aluno acerca de diferentes temas, como diversidades raciais, sexuais e sociais, bem como as tradições, culturas e as organizações sociais (cf. PINSKY, PINSKY, 2009: 23-24). Neste sentido, o profissional do ensino deve buscar novos métodos e perspectivas, a fim de desprender-se de uma única linha de pensamento ou interpretação única dos fatos e períodos históricos.

A disciplina de História está nos currículos escolares desde 1837, sendo inicialmente uma junção de várias disciplinas consideradas "saberes fundamentais" (BITTENCOURT, 2004: 33), porém apenas

Em 1934, foi criado o $1^{\circ}$ curso de História na Faculdade de Filosofia, Ciências e Letras na Universidade de São Paulo e, em 1939, na Faculdade Nacional do Rio de Janeiro, lançando as bases para a profissionalização do historiador e do professor de História (DIAS, 2008: 56).

Percebe-se que somente na década de 1930, com o Decreto n. 19.852 de 1931 é que se organizam os parâmetros didático- administrativos do Ensino Superior, e consequentemente, do ensino de História.

Na década de 1930 o IHGB lançou as bases da historiografia brasileira nas universidades, porém totalmente influenciados pela historiografia tradicional. Somente a partir da década de 1960, influenciadas pelas ciências sociais, as universidades auxiliam de forma significativa na profissionalização do historiador, que começou tratar e debater temas econômicos e sociais. Seguidamente, as décadas de 1970 e 1980 foram importantíssimas para a consolidação e expansão dos cursos de graduação e pós-graduação, resultando na especialização dos profissionais de História no país (cf. CASTRO, 1997: 52)

Sob este pano de fundo, podem-se reunir desde pesquisas em história social do trabalho e da urbanização, em sentido clássico, até as formulações mais recentes relativas à vida cotidiana, às identidades sociais, ao controle social e à cidadania, no espaço urbano (CASTRO, 1997: 54).

Temas vinculados aos movimentos sociais, industriais e urbanos, começam ser abordados, bem como a "história social da família", "história social do trabalho" e a "história social da escravidão no Brasil Colônia”, amplamente debatidos e pesquisados, configurando a 
"história das mentalidades", abordando as identidades sociais brasileiras (cf. CASTRO, 1997: $52-55)$.

Somente com as várias mudanças sociais e políticas instauradas com a promulgação da nova Constituição brasileira em 1988 é que mudanças consideráveis ocorrem na educação, especialmente tratando-se de História. A nova Lei de Diretrizes e Bases da Educação Nacional em 1996 (LDB 9.394/96), bem como os Parâmetros Curriculares Nacionais para o ensino (PCNs) estabelecidos em 1997 visam à inclusão da diversidade social, cultural e étnica brasileira no ensino de História (cf. FONSECA, 2003: 32), que juntamente com as Diretrizes para o ensino de História em 2001, definem um novo modelo de ensino, visando uma melhor formação do profissional da educação (cf. FONSECA, 2010: 1-2).

A partir da história da História é que foram pensadas novas formas de "ensinar e aprender". Com as Diretrizes Curriculares de História de 2001, diferentes materiais e práticas foram incorporados ao ensino perante as escolas. Novos ideais foram criados visando uma nova formação tanto do aluno, como do professor. O período do curso foi alterado bem como a grade acadêmica, os estágios e as atividades complementares modificados em prol de uma formação mais estável e aperfeiçoada. O ensino de História ganha maior visibilidade e importância, tanto nas universidades como nas redes básicas de ensino (cf. FONSECA, 2003: 35-37), (cf. FONSECA, 2010: 1-2).

Dois anos mais tarde, a Lei n. 10.639/03 de 2003 tornou obrigatória a inclusão de "História e Cultura Afro-Brasileira e Africana", alterada em 2008 pela Lei 11.645/08 tornando obrigatório o conteúdo de "História e Cultura Afro-Brasileira e Indígena". Essas leis acabam alterando a LDB de 1996. Constatam-se modificações nos métodos e conteúdos, buscando uma inclusão abrangente das diferentes culturas e etnias que compõem a sociedade brasileira - para que assim, o aluno aprenda também sobre a sua própria nação (cf. FONSECA, 2010: 4).

O ensino de História envolve relações culturais, políticas e sociais, cria as bases para o consenso de cidadania e consciência crítica e histórica dos alunos. Perpassa por diversos tempos, espaços, sujeitos, saberes, culturas e etnias, visando englobar toda a sociedade em busca de conhecimento e desenvolvimento da mesma. "Trata-se, pois, de um exercício complexo, um ato político, cultural e pedagógico" (FONSECA, 2010: 6).

O foco tornou-se o "ensino- aprendizagem" e não apenas o ensino. Desta forma preocupava-se com o desempenho do aluno, em saber se ele realmente aprendeu aquilo que foi proposto. Até o século XX a formação de professores seguia o padrão tradicional, onde o

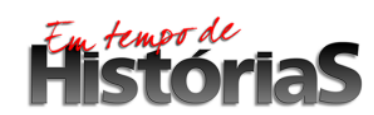


professor era a autoridade máxima em sala de aula, e sua tarefa era apenas a de "repassar" o conhecimento aos alunos, sem a preocupação com a aprendizagem (cf. DIAS, 2008: 52).

A nova formação acadêmica proporciona aos professores uma nova visão e instrução, percebendo deste modo, que novas formas de ensino são possíveis. Uma ampliação nos temas, debates e possibilidades de fontes para o ensino começam ser formadas e revistas, a fim de modificar os parâmetros curriculares visando atingir os alunos de maneira significativa acerca do passado e do presente em que se inserem, acolhendo as minorias e diferentes experiências históricas (cf. FONSECA, 2003: 32-36).

Assim como os profissionais do ensino, o próprio estudo da História está em constante mudança, buscando novas perspectivas e interpretações do passado, portanto, estudar os diferentes pontos e abordagens de um mesmo fato, resulta em novas e diferentes visões sobre esse passado/fato em questão, o que oferece melhores respostas e compreensões acerca de tudo que já foi vivido (cf. JENKINS, 2001: 35).

Ao longo dos anos, teorias da história, metodologias de pesquisa e tendências historiográficas são criadas e utilizadas para auxiliar na interpretação e estudo da História e seus fatos. A partir disso, as perguntas são criadas, os métodos de pesquisa são incorporados e análises e interpretações feitas, buscando respostas acerca de fatos e períodos históricos (cf. CALDAS, 2010: 10-15). Sendo que

A responsabilidade ética, política e profissional do ensinante lhe coloca o dever de se preparar, de se capacitar, de se formar antes mesmo de iniciar sua atividade docente. Esta atividade exige que sua preparação, sua capacitação, sua formação se tornem processos permanentes. Sua experiência docente, se bem percebida e bem vivida, vai deixando claro que ela requer uma formação permanente do ensinante. Formação que se funda na análise crítica de sua prática (FREIRE, 2001: 259).

A História é um estudo voltado ao passado como também ao presente, o qual deve ser registrado, investigado e interpretado. Neste sentido a História é o estudo das ações do homem no tempo, o que possibilita conhecer e comparar sociedades e suas organizações durante diferentes períodos e espaços. "Portanto, todos os registros e as evidências das ações humanas são fontes de estudo da história" (FONSECA, 2003: 40), pois são representações do mundo.

Desta forma percebe-se que a História não trata apenas do passado - apesar de ser seu principal objeto de estudo - mas busca evidências no passado, para através dele, compreender o presente (JENKINS, 2001: 23-24). Sendo assim, a História tanto como Ciência ou Disciplina,

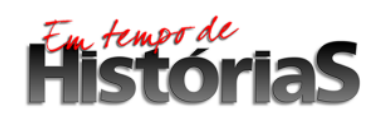


nos serve como orientação de mundo, pois conforme se conhece o "outro" e a forma social em que ele vive com os valores que possui e o momento histórico em que se encontra, o aluno consegue perceber as permanências e rupturas de determinado meio social.

Porém, para que isso seja possível, os alunos também devem se perceber como sujeitos históricos, somente assim o ensino de História começa fazer sentido, pois o aluno começa pesquisar a história e o passado, em busca de respostas para questões e comportamentos sociais que existem em seu presente, formando-se como cidadão crítico (cf. PINSKY, PINSKY, 2009: 21).

É papel do professor não somente ensinar o passado, mas também contextualizar o conteúdo com a realidade presente em que o aluno se insere, tendo como principal objetivo auxiliá-los na tomada da consciência história e análise do seu presente, o qual não deixa de ser um fato histórico (cf. CERRI, 2010: 271-272). Deste modo fica evidente que o professor precisa se desprender do tradicional, buscando sempre novos métodos de ensino- aprendizagem, se desvinculando da dependência total do livro didático, por exemplo - que já tem conteúdo pronto e que geralmente apresenta apenas uma visão dos fatos.

Pode preferir-se uma abordagem verdadeiramente epistemológica examinando as relações entre a história e as ciências vizinhas: a geografia, a demografia, a economia, a sociologia, a etnologia, a lingüística, a psicanálise, etc. Podemos limitar-nos a melhorar "a ferramenta de trabalho" inventoriando as técnicas auxiliares da história como a arqueologia, a epigrafia, a paleografia, a cartografia, a estatística, e, hoje, a informática. Pode considerarse o papel social da história apreciando o ensino da disciplina na universidade, no liceu, na escola; avaliando a sua difusão pelos livros e as revistas, pelo cinema, a rádio ou a televisão. Todos estes modos de observação são legítimos e merecem que lhes consagrem análises aprofundadas (BOURDÉ, MARTIN, 1983: 9).

É fundamental problematizar, instigar o pensamento e desta forma, utilizar de outras fontes que ilustram e contam a história de uma maneira diferente, pois

Para colocar em prática essas propostas curriculares do ensino de História é relevante que o educador considere novas possibilidades de trabalho pedagógico, em que os educandos sejam motivados a construir e a reconstruir conceitos, vivenciando momentos em que possam pesquisar coletar informações em diversas fontes, discutir, refletir e relacionar-se de maneira a colaborar para o desenvolvimento de sujeitos ativos e criativos (SILVA, OLIVEIRA, ARANA, 2016: 48).

\section{Hitistorias}


A consciência histórica não é uma condição que surge com determinada classe social, período ou região; mas a partir do momento em que o sujeito detém a noção de que sua cultura, suas bases e regras de convivência em sociedade são estabelecidas a partir de outros tempos e sociedades. Com o tempo a humanidade supera e aprimora suas formas de vivência, não há um controle sobre isso, portanto, aceitar esse "processo histórico" libertando-se de preconceitos e "limites" impostos por sua própria cultura, determina o surgimento da consciência histórica no indivíduo (cf. CERRI, 2001: 99-101).

Como apresentado anteriormente, o ensino de História se molda conforme o momento em que está sendo ensinado. Ter essa consciência é de fundamental importância para o aluno aprender criticar, pensar e analisar diferentes pontos de vista, sendo o professor o mediador desse processo. Portanto, o aprendizado nunca pode ser mecânico, ainda mais se tratando de História, onde há várias visões de um fato e vários objetivos e interesses por trás dos discursos (cf. JENKINS, 2001: 41-42). Desta forma a análise crítica e o conhecimento histórico são fundamentais para a formação de sujeitos que busquem veracidade, se tornando livres de supostas manipulações de fatos e da história como um todo.

A consciência histórica do aluno começa a ser formada antes mesmo do
processo de escolarização e se prolonga no decorrer de sua vida, fora da
escola, em diferentes espaços educativos, por diferentes meios. Assim, a
construção de uma prática de ensino de História que de fato objetive a
formação de cidadãos críticos, requer a valorização permanente das vozes dos
diferentes sujeitos, do diálogo, do respeito à diferença, bem como o combate
às desigualdades e o exercício da cidadania em todos os espaços (FONSECA,
2010: 11).

Para analisar documentos, relatos, imagens ou qualquer fonte histórica, o aluno deve ter a noção de que a cultura e os modos de pensar, as formas de escrita e os significados atribuídos àqueles documentos têm formas distintas de compreensão. Isso porque vivemos em um mundo com diversas culturas, religiões, costumes, e tudo isso deve ser levado em consideração, não podemos atribuir nossa forma de pensar para analisar um documento, mas sim, buscar compreender o contexto histórico que a fonte foi produzida.

É importante estudar a fonte e sua produção analisando o determinado período ao qual foi criada, justamente por elas servirem como uma manobra de contestação, aceitação ou outra forma de demonstração social da época. Sendo essa contestação voltada ao cultural, social e ideológico, (re)construindo os fatos do cotidiano do autor da fonte em si (cf. MACÊDO, SOUZA, 2008: 2-3).

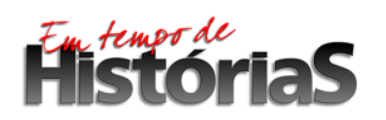

(PPGHIS/UnB) №. 32, Brasília, Jan - Jul 2018 ISSN 2316-1191 
As imagens que interessam ao historiador são imagens coletivas, amassadas pelas vicissitudes da história, e que se formam, modificam-se, transformamse. Exprimem-se em palavras e em temas. (LE GOFF, 1994: 16).

Essa leitura da fonte é de fundamental importância, pois deixa transparecer algumas críticas que podem instigar uma reflexão do que está ocorrendo na sociedade. Por isso é de fundamental importância trabalhar também com outros tipos de fonte em sala de aula, para que assim os alunos possam "enxergar" a história por um olhar diferente, percebendo-se também como parte dessa história (cf. FONSECA, 2003: 37), (cf. PEREIRA, SEFFNER, 2008: 114).

Quando compreendemos nossa vivência, nós nos reconhecemos como sujeitos históricos, a partir de então, percebemos o mundo em que vivemos e, principalmente, compreendemos quem nós somos e quais nossas origens. Somente assim teremos bagagem e conhecimento suficiente para conseguirmos mudar, desenvolver, criar nosso futuro, e desta forma prosseguir com a construção da História.

\section{Considerações Finais}

Esta pesquisa aborda a contextualização da educação no Brasil, apresentando as diversas fases do ensino, elencando como as influências econômicas, sociais e políticas auxiliaram para o progresso da educação e da disciplina de História no âmbito curricular.

Inicialmente o objetivo da educação no Brasil estava vinculado ao meio religioso por meio da catequização dos índios pelos padres jesuítas, em seguida substituídos pelos meios filosóficos, evoluindo para uma educação moral e cívica no século XIX. Posteriormente, em meio à ditadura militar, disciplinas que estimulavam/instigavam o pensamento crítico e filosófico do aluno - assim como a disciplina de História - foram retiradas do currículo escolar.

Fica evidente que desde o século XIX o ensino - especificamente de História - era visto como "instrumento pedagógico" e político, objetivando a construção da história do país e da identidade nacional, o que foi enfatizado no decorrer do século XX.

Neste contexto, é possível destacar que as transformações da educação se deram por interesses do Estado. Com a educação amplamente vinculada a essas propensões, o mesmo ocorreu com o ensino de História. Portanto, não apenas a História como disciplina deve ser analisada, mas também o momento em que está sendo ensinada.

\section{Fitistorias}


Em sua obra "Os objetivos do ensino de História" de 1999, Cerri já retratava a importância de compreendermos o momento político, econômico e social em que vivemos e como o ensino de História se torna fundamental para isso.

Como apresentado neste trabalho, com a evolução e a consolidação do ensino de História, esse pensamento foi revisto com objetivo de "libertar" a educação e o ensino de interesses, visando apenas o conhecimento e uma melhor formação de alunos enquanto cidadãos.

Com o atual momento de crise política e educacional - com verbas e gastos voltados à educação reduzidos - a disciplina de História torna-se de fundamental importância, pois não pode ser vista apenas como um estudo do passado ou das formas de organização existentes na sociedade. A História registra fatos, ensina o aluno a pensar, criticar, pesquisar, para que assim, espelhando-se no passado, possa usufruir dos acertos e evite os mesmos erros cometidos nas diferentes sociedades ao longo do tempo.

Buscando sempre se desprender do objeto de análise, não se deixando manipular pela mídia ou pesquisas tendenciosas, cria-se com a História sujeitos críticos que aprendem pesquisar e buscar veracidade ou equívocos dos fatos antes de apontá-los como uma verdade absoluta. Portanto, o uso de fontes históricas em sala de aula e o auxílio do professor para ensinar na análise dessas fontes, são importantíssimos para comprovar esses fatos e definir os moldes do conhecimento científico do aluno, também para auxiliar na criação de uma sociedade mais justa para todos.

O objetivo da História, tanto como ciência como quanto disciplina, é o de formar alunos como sujeitos produtores da história, que observem, descrevam e comparem, não sendo apenas meros expectadores da história já realizada e estabelecida. Desta forma, visando à formação intelectual do sujeito, estimulando sua participação no desenvolvimento da sociedade.

Para finalizar, com as palavras de Paulo Freire, este artigo traz que os sujeitos precisam se inserir no processo histórico em busca de sua afirmação. Com a consciência crítica os indivíduos têm maior facilidade de compreender a realidade dos fatos, inserindo-se, modificando e questionando sua própria forma de ser e agir; pois criticando, problematizando e criando consciência, o homem se (re)descobre como sujeito da História.

\section{Referências Bibliográficas}


ALVES, Gilberto Luiz; CENTENO, Carla Villamaina. A produção de manuais didáticos de história do Brasil: remontando ao século XIX e início do século XX. Revista Brasileira de Educação, Rio de Janeiro, vol. 14, n. 42, 2009

BRASIL. Ministério da Educação. Parecer CNE/CES 492/2001. Diretrizes Curriculares Nacionais dos cursos de Filosofia, História, Geografia, Serviço Social, Comunicação Social, Ciências Sociais, Letras, Biblioteconomia, Arquivologia e Museologia. Brasília (DF): abril de 2001, p. 5-9. Disponível em <http://portal.mec.gov.br/cne/arquivos/pdf/CES0492.pdf> Acesso em: 07/05/2018.

BITTENCOURT, Circe Maria Fernandes. Ensino de História: fundamentos e métodos. São Paulo: Cortez, 2004.

BOURDÉ, Guy; MARTIN, Hervé. As Escolas Históricas. Tradução P. E. A. Portugal: Mira-Sintra. 1983

CALDAS, Pedro Spinola Pereira. Teoria e Prática da Metodologia da Pesquisa Histórica: Reflexões sobre uma Experiência Didática. Revista da Teoria da História, Goiás, ano 1, n. 3, 2010

CASTRO, Hebe. "História social". In: Domínios da história: ensaios de teoria e metodologia. Ciro F. CARDOSO; Ronaldo. VAINFAS (orgs.), Rio de Janeiro: Campus, 1997

CERRI, Luis Fernando. A formação de professores de História no Brasil: Antecedentes e panorama atual. História, histórias, Brasília, vol. 1, n. 2, 2013

CERRI, Luis Fernando. Didática da História: uma leitura teórica sobra a História na prática. Revista de História Regional, Ponta Grossa, vol. 15, n. 02, ed. de inverno, 2010

CERRI, Luis Fernando. Os conceitos de consciência histórica e os desafios da didática da História. Revista de História Regional, Ponta Grossa, vol. 6, n. 2, ed. de inverno. 2001

CERRI, Luis Fernando. Os objetivos do ensino de História. Revista História \& Ensino, Londrina, vol. 5, 1999

DIAS, Sueli de Fátima. A prática pedagógica do professor de História: um estudo de suas percepções nos colégios estaduais de Apucarana-PR (1990). Londrina, 2008.

FERRO, Marc. A manipulação da história no ensino e nos meios de comunicação. São Paulo: IBRSA, 1983

FONSECA, Selva Guimarães.Didática e Prática de Ensino de História: Experiências, reflexões e aprendizados. Campinas: Papirus, 2003.

FONSECA, Selva Guimarães. A História na educação básica: conteúdos, abordagens e metodologias. Anais do I Seminário Nacional: Currículo em Movimento - Perspectivas atuais. Belo Horizonte, novembro de 2010

FONSECA, Selva Guimarães; COUTO, Regina Célia do. “A Formação de Professores de História no Brasil: Perspectivas desafiadoras no nosso tempo". In: Espaços de formação do professor de História. / Selva Guimarães Fonseca, Ernesta Zamboni (orgs.)-Campinas: Papirus, 2008

FREIRE, Paulo. Pedagogia do oprimido. 17ª ed., Rio de Janeiro: Paz \& Terra, 1970.

FREIRE, Paulo. Carta de Paulo Freire aos professores. Estudos Avançados, São Paulo, vol. 15, n. 42, 2001

GADOTTI, Moacir. Perspectivas atuais da educação. São Paulo em Perspectiva, São Paulo, vol. 14, n. 2, 2000

GHIRALDELLI, Paulo. Introdução à Educação Escolar Brasileira: História, Política e Filosofia da Educação [Versão Prévia]. São Paulo, 2001.

GUIMARÃES, Manoel Luis Salgado. Nação e Civilização nos Trópicos: O Instituto Histórico e Geográfico Brasileiro e o Projeto de uma História Nacional. Estudos Históricos. Rio de Janeiro, vol. 1, n. 1, 1988

JENKINS, Keith. “O que é a História?”. In: A História Repensada. Tradução: Mário Vilela. São Paulo: Contexto, 2001

LE GOFF, Jacques. O imaginário medieval. Tradução: Manuel Ruas. $1^{\mathrm{a}}$ ed. Coleção Nova História, vol. 13. Lisboa: Editorial Estampa, 1994.

MACÊDO, José Emerson Tavares de; SOUZA, Maria Lindaci Gomes de. A charge no ensino de história. Anais do XIII Encontro Estadual de História - Guarabira, 2008

MACIEL, Lizete Shizue Bomura;SHIGUNOV, Alexandre. A educação brasileira no período pombalino: uma análise histórica das reformas pombalinas do ensino. Educação e Pesquisa, São Paulo, vol.32, n. 3,2006

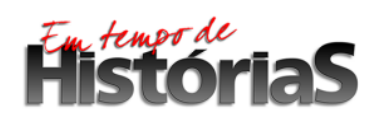

(PPGHIS/UnB) No. 32, Brasília, Jan - Jul 2018 ISSN 2316-1191 
MENDONÇA, Ana Waleska P. C.; LOPES, Ivone Goulart; SOARES, Jefferson da Costa; PATROCLO, Luciana Borges. A criação do Colégio de Pedro II e seu impacto na constituição do magistério público secundário no Brasil. Educação e Pesquisa, São Paulo, vol. 39, n. 4, 2013

MENEZES, Fernando Vendrame. A Educação e o ensino de História no Brasil: alguns apontamentos. Anais do XXVI Simpósio Nacional de História - ANPUH. São Paulo, 2011

PEREIRA, Nilton Mullet; SEFFNER, Fernando. O que pode o ensino de história? Sobre o uso de fontes na sala de aula. Anos 90. Porto Alegre, vol. 15, n. 28, 2008

PINSKY, Jaime; PINSKY, Carla Bassanezi. “Por uma história prazerosa e conseqüente". In: História na sala de aula: conceitos, práticas e propostas / Leandro Karnal (org.) - 5ª ed., São Paulo: Contexto, 2009

R.IHGB. Revista do Instituto Histórico e Geográfico Brasileiro. Rio de Janeiro, tomo I, n. 1, 1839

SCHWARCZ, Lilia Moritz. O espetáculo das raças: cientistas, instituições e questão racial no Brasil (1870-1930). São Paulo: Companhia das Letras, 1993.

SILVA, Henrique; OLIVEIRA, Jackeline; ARANA, Alba. O papel dos PCN's: O ensino de História no Brasil. Colloquium Humanarum, Presidente Prudente, vol. 13, n. 3, 2016

SILVA, Isaíde Bandeira da. O Livro Didático de História: Escolhas, usos e percepções de professores e alunos no cotidiano escolar. Educação e Filosofia, Uberlândia, vol. 26, n. 52, 2012.

YAMAMOTO, Oswaldo H. Educação e tradição marxista no Brasil. Revista Comunicação \& Educação, São Paulo vol. único, n. 10, 1997 